\title{
A Chemical Ionization Mass Spectrometer for ambient measurements of Ammonia
}

\author{
D. R. Benson ${ }^{1}$, A. Markovich ${ }^{1}$, M. Al-Refai ${ }^{2}$, and S.-H. Lee ${ }^{1}$ \\ ${ }^{1}$ Kent State University, Department of Chemistry, Kent, Ohio, USA \\ ${ }^{2}$ Kent State University, Department of Computer Sciences, Kent, Ohio, USA
}

Received: 23 February 2010 - Published in Atmos. Meas. Tech. Discuss.: 24 March 2010

Revised: 27 July 2010 - Accepted: 27 July 2010 - Published: 19 August 2010

\begin{abstract}
This study presents a chemical ionization mass spectrometer (CIMS) for fast response, in-situ measurements of gas phase ammonia $\left(\mathrm{NH}_{3}\right)$. The $\mathrm{NH}_{3}$ background level detected with the CIMS ranged between $0.3-1$ ppbv, with an uncertainty of $30 \mathrm{pptv}$ under optimized conditions. The instrument sensitivity varied from $4-25 \mathrm{~Hz} /$ pptv for $>1 \mathrm{MHz}$ of reagent ion signals (protonated ethanol ions), with a $30 \%$ uncertainty estimated based on variability in calibration signals. The CIMS detection limit for $\mathrm{NH}_{3}$ was $\sim 60$ pptv at a 1 min integration time ( 3 sigma). The CIMS time response was $<30 \mathrm{~s}$. This new $\mathrm{NH}_{3}$-CIMS has been used for ambient measurements in Kent, Ohio, for several weeks throughout three seasons. The measured $\mathrm{NH}_{3}$ mixing ratios were usually at the sub-ppbv level and higher in spring (200 \pm 120 pptv) than in winter $(60 \pm 75 \mathrm{pptv})$ and fall $(150 \pm 80 \mathrm{pptv})$. High emissions of $\mathrm{SO}_{2}$ from power plants in this region, and thus possible high acidity of aerosol particles, may explain these low $\mathrm{NH}_{3}$ mixing ratios in general.
\end{abstract}

\section{Introduction}

Ammonia $\left(\mathrm{NH}_{3}\right)$ is prevalent in the atmosphere and serves as the principal basic gas phase species. $\mathrm{NH}_{3}$ can control the acidity of atmospheric aerosols and in turn, change the chemical composition, reactivity, hygroscopicity, and optical properties of aerosol particles. Atmospheric observations (Weber et al., 1998; McMurry et al., 2005) and aerosol microphysical modeling simulations (Stanier et al., 2004; Gaydos et al., 2005; Lucas and Akimoto, 2006; Jung et al., 2008) have suggested that $\mathrm{NH}_{3}$ can be important for atmospheric nucleation on the global and regional scale. Chem-

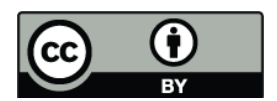

Correspondence to: S.-H. Lee (slee19@kent.edu) ical analysis of aerosol composition also showed that newly formed atmospheric aerosol particles indeed contain ammonium $\left(\mathrm{NH}_{4}^{+}\right)$and sulfate $\left(\mathrm{SO}_{4}^{2-}\right)$ along with other components (Smith et al., 2005). Laboratory nucleation observations (Ball et al., 1999; Benson et al., 2009) further demonstrated that $\mathrm{NH}_{3}$ can enhance sulfuric acid and water homogeneous nucleation (Merikanto et al., 2007).

Sources of $\mathrm{NH}_{3}$ stem mostly from anthropogenic emissions such as livestock excrement, biomass burning, fertilizer application, and automobile emissions (Schlesinger and Hartley, 1992; Dentener and Crutzen, 1994; Fraser and Cass, 1998; Kean et al., 2000; Moeckli et al., 2004; Clarisse et al., 2009). Tropospheric $\mathrm{NH}_{3}$ mixing ratios $\left(\left[\mathrm{NH}_{3}\right]\right)$ range from several pptv up to several hundreds ppbv and sometimes even up to several hundreds ppmv levels (Gilliland et al., 2003; Huai et al., 2003; Herndon et al., 2005; Li et al., 2006; Nowak et al., 2007), depending on the proximity to emission sources, altitude, and acidity of aerosol particles present in the atmosphere. Since even sub ppbv levels of $\left[\mathrm{NH}_{3}\right]$ may be responsible for nucleation events observed in certain atmospheric conditions (Gaydos et al., 2005; Jung et al., 2008) and because nucleation occurs rapidly, it is important to develop a technique capable of measuring low [ $\left.\mathrm{NH}_{3}\right]$ with a fast time response, so that we can identify the role of $\mathrm{NH}_{3}$ in aerosol nucleation from in-situ real-time observations.

Reliable measurements of $\mathrm{NH}_{3}$ are difficult, because of different forms present in the atmosphere, for example, gaseous $\mathrm{NH}_{3}$, particulate $\mathrm{NH}_{4}^{+}$(found in compounds such as $\left(\mathrm{NH}_{4}\right)_{2} \mathrm{SO}_{4}, \mathrm{NH}_{4} \mathrm{HSO}_{4}$, and $\left.\mathrm{NH}_{4} \mathrm{NO}_{3}\right)$, and liquid $\mathrm{NH}_{4} \mathrm{OH}$. $\mathrm{NH}_{3}$ is also a very sticky molecule, so when even extremely clean air is introduced into the sampling inlet, there are always substantial $\mathrm{NH}_{3}$ signals (background signals) due to adsorption and desorption of $\mathrm{NH}_{3}$ on various surfaces; and, the instrument detection limit is ultimately dependent on the background signals. The instrument time response is also

Published by Copernicus Publications on behalf of the European Geosciences Union. 
(a)

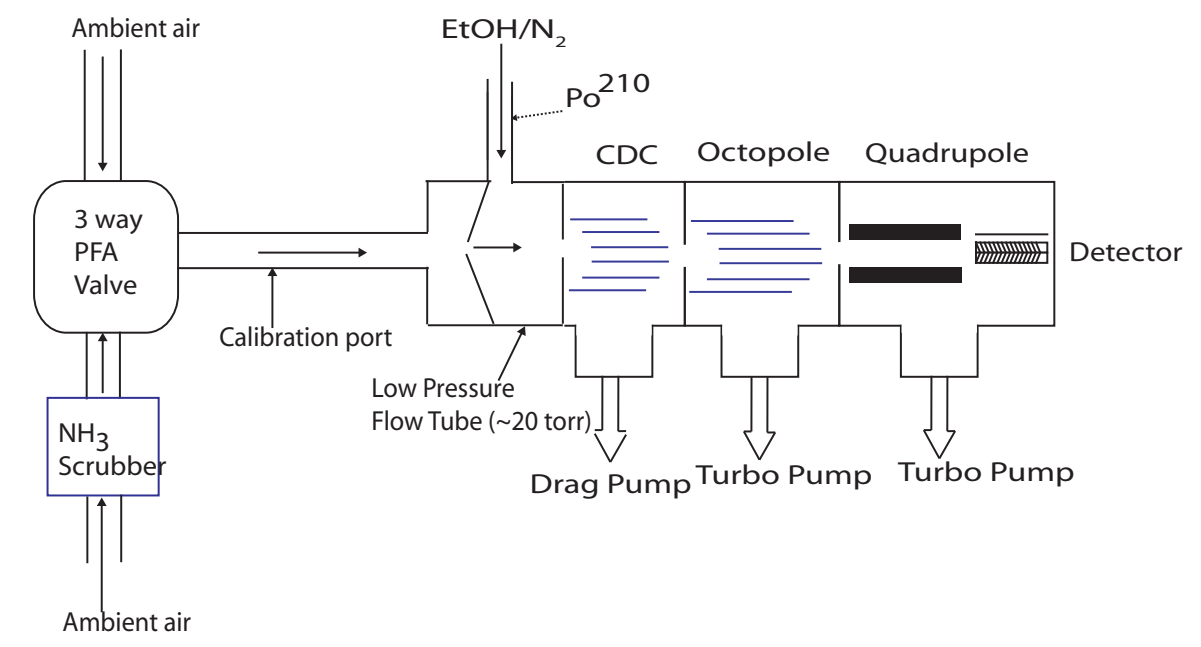

Fig. 1a. The $\mathrm{NH}_{3}$-CIMS system consists of the following three parts: (i) a sampling inlet used for ambient, background and calibration measurements, (ii) the CIMS flow reactor where ion-molecule reactions occur, and (iii) the vacuum regions of the mass spectrometer including a collision dissociation chamber (CDC), an octopole ion guide, a quadrupole mass filter and a channeltron detector.

affected by adsorption and desorption of $\mathrm{NH}_{3}$ on the inlet and instrument surfaces. Uncertainties in the background and calibration measurements also need to be addressed for the accurate detection of $\mathrm{NH}_{3}$.

Different measurement techniques have been developed, including citric acid denuder/ion chromatography (Ferm et al., 1988; Fehsenfeld et al., 2002), molybdenum-oxide converter-difference (Langford et al., 1989), tungsten oxide denuder (Lebel et al., 1985), photofragmentation/laser induced fluorescence (van Dijk et al., 1989), and filterpack/colorimetry (Quinn and Bates, 1989). The citric acid denuder/ion chromatography technique is the most commonly used method, as this technique has a high accuracy (within 10\%), a simple system, a low cost as well as a low detection limit for the chromatographic system (as low as $25 \mathrm{pptv}$ ) (Fehsenfeld et al., 2002). For these reasons, it has also served as the standard method to which the other techniques are judged, but the time resolution is poor (e.g., $2 \mathrm{~h}$ sampling period) (Schwab et al., 2007) have also discussed several different methods of $\mathrm{NH}_{3}$ measurements, such as ion mobility spectrometer, tunable diode laser absorption spectrometer, long path absorbtion photometer, wet effluent diffusion denuder and chemiluminescence analyzer. While most of these instruments have a low detection limit $(<200$ pptv) with 1 min integration time, some of the instruments also have a slow response time. More recent methods include Quantum Cascade Tunable Infrared Laser Differential Absorption Spectrometer or QC-TILDAS (Ellis et al., 2010), Gradient of Aerosol and Gases Online Registrator (GRAEGOR) (Thomas et al., 2009) and Infrared Atmospheric Sounding Interferometer Spectrometer or IASI Spectrometer (Clarisse et al., 2009).
Recently, chemical ionization mass spectrometers (CIMS) have been used for fast time resolution detection for $\mathrm{NH}_{3}$ (Nowak et al., 2006, 2007; Norman et al., 2007; von Bobrutzki et al., 2010). These instruments were used in both ground-based (Nowak et al., 2006; Norman et al., 2007; von Bobrutzki et al., 2010) and aircraft studies (Nowak et al., 2007). A summary of $\mathrm{NH}_{3}$-CIMS from these pre-existing techniques is given in Table 1 and will be discussed in detail in Sect. 5 in comparison with our CIMS. The major advantage of CIMS, compared to other techniques, is fast time response $(<1 \mathrm{~min})$. On the other hand, the lowest reported background in CIMS is only about a few hundred pptv and the stability of the background can be poor (Nowak et al., 2006).

The present study describes a CIMS instrument for in-situ $\mathrm{NH}_{3}$ detection. Our focus is to address these technical issues including the instrument background, calibration and time response. We also include the seasonal variation of $\mathrm{NH}_{3}$ in Kent, Ohio (a relatively less polluted US Midwestern town) in this study to demonstrate the instrument capability for atmospheric observations. The purpose of measuring $\mathrm{NH}_{3}$ at this site is to understand the $\mathrm{NH}_{3}$ effects on aerosol nucleation, but the influence of $\mathrm{NH}_{3}$ and sulfuric acid $\left(\mathrm{H}_{2} \mathrm{SO}_{4}\right)$ on aerosol abundance is discussed elsewhere (Erupe et al., 2010). In an additional paper (Kanawade et al., 2010, Observations of ultrafine particle sizes, sulfuric acid, and ammonia in the Michigan Forest during the PROPHET 2009 CABINEX mission, in preparation; hereinafter referred to as Kanawade et al., 2010), we also show the inter-comparison results of $\mathrm{NH}_{3}$ instruments in the Michigan forest, with a large number of gas phase species and aerosol measurements. 


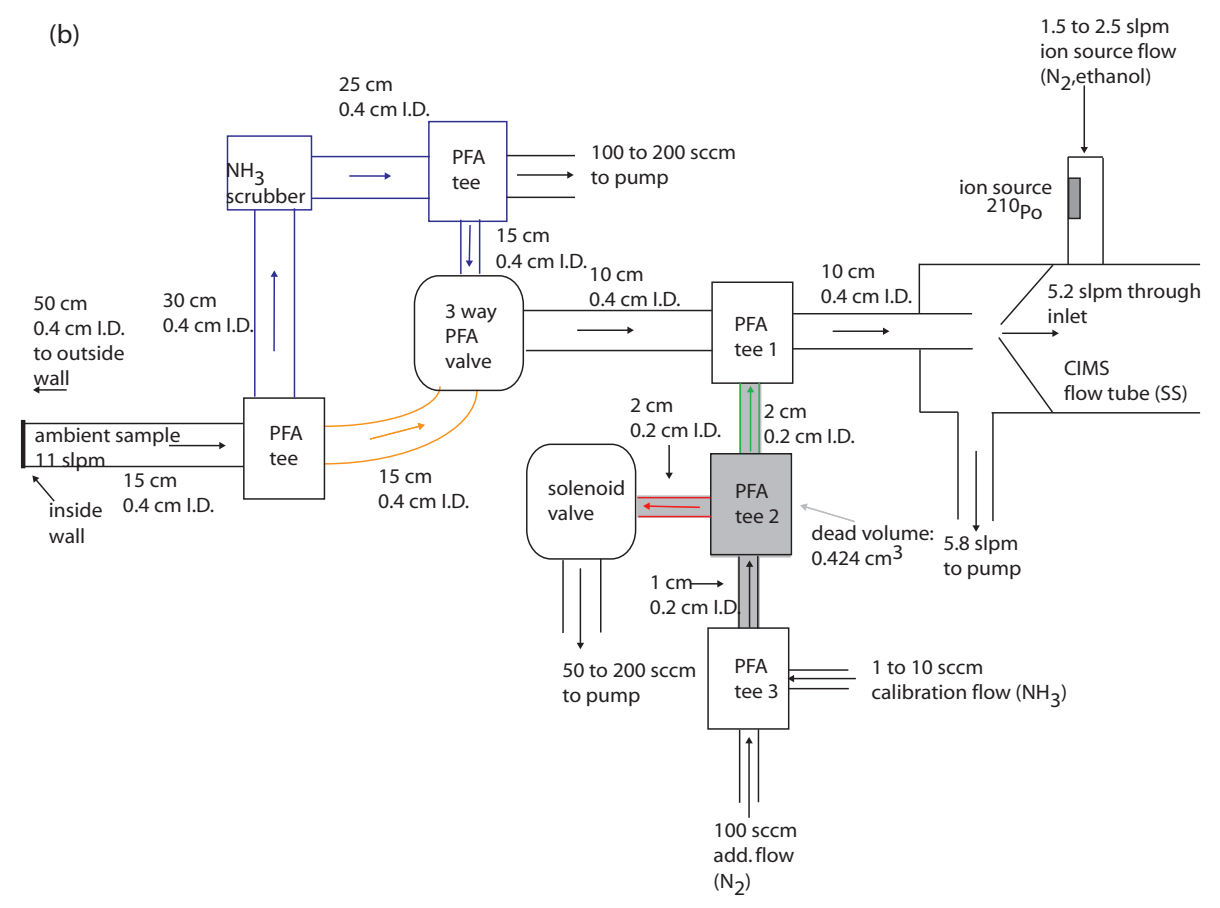

Fig. 1b. A schematic diagram of the inlet of KSU NH 3 -CIMS used in the fall 2009 measurements. The air entered through an inlet port (11 slpm) and traveled through a PFA tee. The air flowed either directly through a 3-way PFA valve (measurement mode, orange arrow) or through an $\mathrm{NH}_{3}$ scrubber and into the PFA valve (background mode, blue arrows). Calibration gases were introduced to the CIMS inlet system at the downstream of the 3-way valve. An additional flow $(100 \mathrm{sccm})$ of $\mathrm{N}_{2}$ gases was also brought to the calibration system to mix with the standard $\mathrm{NH}_{3}$ gases, to increase the time response with a high flow. This time response was affected by both the flow rate of gases and the dead volume (shown in the grey shaded area; estimated to be $0.4 \mathrm{~cm}^{3}$ ) in the tubing. When taking ambient or background measurements, the added calibration gases were removed by the suck back flow through a solenoid valve (red arrow), to reduce perturbation of flow. During the calibration, this solenoid valve was closed, so that calibration gases were introduced into the CIMS inlet system (green arrow).

\section{Instrument}

The $\mathrm{NH}_{3}$-CIMS consists of the following three parts: (i) a sampling inlet used to perform ambient, background and calibration measurements, (ii) the CIMS flow reactor where ionmolecule reactions take place, and (iii) the vacuum region of the mass spectrometer including a collision dissociation chamber (CDC), an octopole ion guide, a quadrupole mass filter and a channeltron detector (Fig. 1a). The third part of the CIMS (vacuum region) is similar to that of the Georgia Tech $\mathrm{NH}_{3}$-CIMS (Nowak et al., 2006, 2007) and of the $\mathrm{H}_{2} \mathrm{SO}_{4}$-CIMS described elsewhere (Eisele and Tanner, 1993; Slusher et al., 2004; Benson et al., 2008; Young et al., 2008). The CDC and octopole ion guide dramatically improve the cleanness of ion mass spectra and the instrument sensitivity (Fig. 1a) (Sect. 2.3). This is one of the major advantages of our CIMS, along with some $\mathrm{NH}_{3}$-CIMS instruments (Nowak et al., 2006, 2007), compared to a number of other CIMS instruments currently used for atmospheric observations of various trace gas species. Below, we only describe the inlet and the ion-molecule reaction region (Sects. 2.2 and 2.3).
We also note that our CIMS is designed to measure gas phase $\mathrm{NH}_{3}$, as opposed to $\mathrm{NH}_{4}^{+}$present in solid or liquid aerosol phases. This is because CIMS techniques in principle are based on gas phase ion-molecule reactions (e.g., Reaction 1 in Sect. 2.3). To detect aerosol phase $\mathrm{NH}_{4}^{+}$, typically, aerosol particles must be first deposited for a substantial period to collect a sufficient volume of aerosol phase $\mathrm{NH}_{4}^{+}$, which are then vaporized into the gas phase by thermal desorption or laser ablation for further ionization. But this is not the case for our CIMS which ionizes only gas phase $\mathrm{NH}_{3}$ molecules using protonated ethanol ions (Sect. 2.3).

There is also the possibility that volatilization of ammonium nitrate $\left(\mathrm{NH}_{4} \mathrm{NO}_{3}\right)$ from various surfaces of the instrument can contribute to the measured $\mathrm{NH}_{3}$ ion signals, but the volatilization is usually negligible for temperatures under $50^{\circ} \mathrm{C}$ and residence times (in the inlet) less than $0.05 \mathrm{~s}$ (Neuman et al., 2003). Because our temperature $\left(35^{\circ} \mathrm{C}\right)$ was lower than this and inlet residence time $(0.068 \mathrm{~s})$ was comparable, there should not be any bias in the signal due to volatile $\mathrm{NH}_{4}^{+}$aerosol. Another study (Fehsenfeld et al., 2002) also confirmed that $\mathrm{NH}_{4}^{+}$volatilization in mass spectrometer systems is limited for time scales less than one second. As will 
Table 1. A summary of $\mathrm{NH}_{3}$-CIMS instruments found in the literature, with regard to sampling inlet and CIMS detection conditions. Included here are the configuration of the 3-way valve used to switch between the ambient and calibration mode; temperature, flow rate, total length and inner diameter of the sampling inlet; residence time for ambient measurements through the inlet; pressure and residence time in the CIMS flow tube reactor; the reagent ion used for analysis; sensitivity, background, and time response of the CIMS instrument.

\begin{tabular}{|c|c|c|c|c|c|c|c|c|c|}
\hline \multicolumn{2}{|l|}{ Reference } & $\begin{array}{l}\text { 3-way valve } \\
\text { Configurationg }\end{array}$ & \multicolumn{2}{|c|}{$\begin{array}{l}\text { Inlet } \\
\text { Temperature }\left({ }^{\circ} \mathrm{C}\right)\end{array}$} & \multicolumn{2}{|c|}{$\begin{array}{l}\text { Inlet Flow Rate } \\
\text { (slpm) }\end{array}$} & $\begin{array}{l}\text { Inlet } \\
\text { Length }\end{array}$ & $\begin{array}{l}\text { Inlet } \\
\text { I.D. } \\
(\mathrm{cm})\end{array}$ & $\begin{array}{l}\text { Inlet } \\
\text { Residence } \\
\text { Time (ms) }\end{array}$ \\
\hline \multicolumn{2}{|l|}{ Nowak et al. $(2006)^{\mathrm{a}}$} & Straight & 50 & & 4 & & 45 & $0.4,0.64$ & 200 \\
\hline \multicolumn{2}{|l|}{ Nowak et al. $(2006)^{b}$} & Straight & 40 & & 13.6 & & 40 & 0.65 & 50 \\
\hline \multicolumn{2}{|l|}{ Nowak et al. $(2007)^{\mathrm{c}}$} & Straight & 30 & & 8 & & 55 & $0.4,0.8$ & 190 \\
\hline \multicolumn{2}{|l|}{ Norman et al. $(2007)^{\mathrm{d}}$} & NA & NA & & 15 & & 1700 & 1.27 & NA \\
\hline \multicolumn{2}{|c|}{ von Bobrutzki et al. $(2010)^{\mathrm{e}}$} & NA & 40 & & 19.5 & & 10 & 0.95 & NA \\
\hline \multicolumn{2}{|l|}{ This study ${ }^{\mathrm{f}}$} & Bent & $35^{\mathrm{h}}$ & & $5.2-15$ & & $100^{\mathrm{i}}$ & 0.4 & $68^{\mathrm{k}}$ \\
\hline Reference & \multicolumn{2}{|c|}{$\begin{array}{l}\text { CIMS } \\
\text { Flow Tube } \\
\text { Pressure } \\
\text { (torr) }\end{array}$} & $\begin{array}{l}\text { CIMS } \\
\text { Flow Tube } \\
\text { Residence } \\
\text { Time }(\mathrm{ms})^{1}\end{array}$ & \multicolumn{2}{|c|}{$\begin{array}{l}\text { Reagent } \\
\text { Ion }\end{array}$} & \multicolumn{2}{|c|}{$\begin{array}{l}\text { Sensitivity } \\
\text { (Hz/pptv) }\end{array}$} & $\begin{array}{l}\text { Background } \\
\text { (ppbv) }\end{array}$ & $\begin{array}{l}\text { CIMS Time } \\
\text { Response to } \\
\text { Calibration } \\
\text { Gases (s) }\end{array}$ \\
\hline Nowak et al. $(2006)^{\mathrm{a}}$ & \multicolumn{2}{|c|}{ Atmospheric Pressure } & NA & \multicolumn{2}{|c|}{$\mathrm{CH}_{3} \mathrm{CH}_{2} \mathrm{OH} \cdot \mathrm{H}^{+}$} & 1 & & $0.1-1$ & 10 \\
\hline Nowak et al. $(2006)^{b}$ & \multicolumn{2}{|l|}{20} & 20 & \multicolumn{2}{|c|}{$\mathrm{CH}_{3} \mathrm{CH}_{2} \mathrm{OH} \cdot \mathrm{H}^{+}$} & 40 & & $1-2$ & 45 \\
\hline Nowak et al. $(2007)^{\mathrm{c}}$ & \multicolumn{2}{|c|}{$18-22$} & $95-160$ & \multicolumn{2}{|c|}{$\mathrm{CH}_{3} \mathrm{COCH}_{3} \cdot \mathrm{H}^{+}$} & $2.6-5$ & & $0.5-1.3$ & 5 \\
\hline Norman et al. (2007) ${ }^{\mathrm{d}}$ & \multicolumn{2}{|l|}{1.5} & $0.100-0.15$ & \multicolumn{2}{|l|}{$\mathrm{O}_{2}^{+}$} & 0.04 & & $0.07-0.47$ & 30 \\
\hline Bobrutzki et al. $(2010)^{\mathrm{e}}$ & \multicolumn{2}{|l|}{ NA } & NA & \multicolumn{2}{|c|}{$\mathrm{H}^{+}\left(\mathrm{C}_{3} \mathrm{H}_{6} \mathrm{O}\right)_{2}$} & 2.5 & & 0.045 & NA \\
\hline This Study ${ }^{\mathrm{f}}$ & \multicolumn{2}{|c|}{$20-25$} & $25-40$ & \multicolumn{2}{|c|}{$\mathrm{CH}_{3} \mathrm{CH}_{2} \mathrm{OH} \cdot \mathrm{H}^{+}$} & $4-25$ & & $0.3-1$ & 40 \\
\hline
\end{tabular}

a This early version of NOAA-CIMS was used in Atlanta, GA during August 2002 for the Aerosol Nucleation and Real-Time Characterization Experiment (ANARChE). Measurements were performed at an urban site $2 \mathrm{~m}$ above the ground level. $\mathrm{b}$ The Georgia Tech-CIMS was also used for the ANARChE and intercomparison with the early version of NOAA-CIMS was made. ${ }^{\mathrm{c}}$ This upgraded NOAA-CIMS for aircraft measurements was used in the New England Air Quality Study-Intercontinental Transport and Chemical Transformation (NEAQS-ITCT) mission. ${ }^{\mathrm{d}}$ The CIMS instrument was used at $1.2 \mathrm{~m}$ above a grass field treated with fertilizer in Oensingen, Switzerland. ${ }^{\mathrm{e}}$ This CIMS instrument was used in southern Scotland during the intercomparison experiments with a large number of $\mathrm{NH}_{3}$ instruments. ${ }^{\mathrm{f}}$ The KSU-CIMS was used in ambient NH${ }_{3}$ measurements in Kent, Ohio (this study) and in Northern Michigan forests in summer 2009 (Kanawade et al., 2010). ${ }^{\mathrm{g}}$ Straight sampling occurred when the flow path from the tip of the inlet (where ambient air enters) through the 3-way valve and to the CIMS was all straight and no bending occurred. Bent sampling occurred when the ambient air enters the 3-way valve perpendicular to the flow that went into the CIMS as shown in Fig. $1 \mathrm{~b} .{ }^{\mathrm{h}}$ Heating was only performed for the fall measurements. ${ }^{\mathrm{i}} 100 \mathrm{~cm}$ was the total length when taking ambient measurements (including the depth of the wall, $50 \mathrm{~cm}$ ). ${ }^{\mathrm{j}}$ This time was estimated based on the flow rate through the inlet and the inlet tubing dimensions (inner diameter and length). ${ }^{\mathrm{k}}$ Residence time for the ambient measurement mode. ${ }^{1}$ This time was estimated based on the flow rate through the CIMS flow tube and the CIMS inlet dimensions (inner diameter and length).

be discussed in Sects. 3.2 and 3.3, we also did not see any temperature dependences of the instrument background and sensitivity, and this proves that $\mathrm{NH}_{3}$ artifacts from vaporization of $\mathrm{NH}_{4}^{+}$decomposition from the aerosol phases were not significant. While we tried to minimize the effects of volatilization of $\mathrm{NH}_{4} \mathrm{NO}_{3}$ from surfaces by heating the inlet system, we also made frequent background measurements (Sect. 3.2), which ultimately reduces the effects of these artifacts $\mathrm{NH}_{3}$ signals.

\subsection{Measurement site}

The ambient measurements were performed from the top floor of Williams Hall ( $15 \mathrm{~m}$ above the ground level) at Kent State University in Kent, Ohio $\left(41.15^{\circ} \mathrm{N}, 81.36^{\circ} \mathrm{W}\right)$, for several weeks covering three seasons starting from winter of 2008 to fall of 2009 . Kent is a small college town with a population of about 30000 located in Northeastern Ohio. Kent is relatively rural itself, but is also surrounded by three urban cities, about $60 \mathrm{~km}$ southeast of Cleveland, about $30 \mathrm{~km}$ east of Akron, and about $100 \mathrm{~km}$ west from Youngstown. The weather in Ohio is especially humid in summer. Northeastern Ohio is also known for its haze and gray colored sky in winter due to high emission of $\mathrm{SO}_{2}$ from coal burning power plants in this region (http://www.epa.gov/cgi-bin/broker?_service= airdata\&_program=progs.webprogs.emisumry.scl\&_debug= $2 \&$ geotype $=$ st $\&$ geocode $=\mathrm{OH} \&$ geoname $=$ Ohio\&epolmin $=$ .\&epolmax $=. \&$ epol $=S O 2 \&$ sic $=$ \&netyr $=2002 \&$ geofeat $=$ $\&$ mapsize $=$ zsc\&reqtype $=$ getmap). Ohio is also one of the 
states that currently suffer from air pollution problems, failing to attain the US National Air Quality Standards (NAAQS) for ozone and $\mathrm{PM}_{2.5}$ (particulate matter smaller than $2.5 \mu \mathrm{m}$ ) (http://www.epa.gov/air/airtrends/pm.html).

\subsection{Inlet: Background, ambient and calibration mode}

Our inlet system was based on the Georgia Tech $\mathrm{NH}_{3}$ inlet (Nowak et al., 2006), with some differences discussed below. Figure $1 \mathrm{~b}$ illustrates the inlet system used during the fall 2009 measurements. The outer portion of the inlet consisted of a $65 \mathrm{~cm}, 0.635 \mathrm{~cm}$ O.D. fluorinated ethylene propylene (FEP) tube (the depth of the wall of Williams Hall is $50 \mathrm{~cm}$ ) that stuck out a $1.27 \mathrm{~cm}$ hole in our laboratory wall. This tube was connected to a perfluoroalkoxy (PFA) tee. One leg of the tee was connected to the first port of a 3-way PFA valve (ambient mode) and the other leg was connected to the $\mathrm{NH}_{3}$ scrubber housing (stainless steel, $3.5 \mathrm{~cm}$ I.D., $15 \mathrm{~cm}$ long) (background mode). For the ambient measurement mode, the sampling air traveled through this tee and the first port of the 3 -way valve. The ambient mode flow is shown by an orange arrow in Fig. 1b. For the background mode, the sampling air traveled through this same PFA tee and the scrubber housing and the second port of the 3-way valve. The scrubber housing contained silicon phosphates (Perma Pure Inc.), which form phosphoric acid when they are exposed to ambient $\mathrm{RH}$ levels and subsequently remove $\mathrm{NH}_{3}$ from the ambient air (to produce "zero" gases). There was another PFA tee between the scrubber housing and the 3-way valve, which was attached to a pump to constantly suck out $100-200 \mathrm{sccm}$ over the scrubber, to prevent the ambient air from stagnating inside the scrubber. The background mode flows are illustrated in blue arrows in Fig. 1b. In either the background or the measurement mode, the sample air exited through the common port of the 3-way valve and through a second PFA tee to flow into the CIMS inlet $(0.635 \mathrm{~cm}$ I.D.) The flow through the inlet was as high as $15 \mathrm{slpm}$ and the typical residence time in the ambient mode was $68 \mathrm{~ms}$. Of this total flow, $5.2 \mathrm{slpm}$ entered into the CIMS flow reactor and the rest of the flow was vented out via a mass flow controller through a diaphragm pump. The purpose of making (frequent) background measurements is to take into account the artifact $\mathrm{NH}_{3}$ signals that arise from the adsorption/desorption of $\mathrm{NH}_{3}$ on the surfaces of the CIMS inlet.

The sensitivity of the CIMS instrument was measured from a calibration using a known concentration of standard $\mathrm{NH}_{3}$ gases. The standard gases supplied from a source cylinder (Linde, mixing ratio $4.5 \mathrm{ppmv}, \pm 5 \%$ ) were added to the system with the flow between 1-10 sccm via a mass flow controller (MKS, $\pm 0.6 \%$ ), which was regularly calibrated with a DryCal (Bios). The $\mathrm{NH}_{3}$ gases were then added to a PFA tee to mix with an additional flow of $\mathrm{N}_{2}$ gases $(50-100 \mathrm{sccm})$ from a liquid nitrogen Dewar (Linde). These additional $\mathrm{N}_{2}$ gases were needed so that the calibration was carried out with a high flow to ensure a fast time response (Sect. 3.1). This

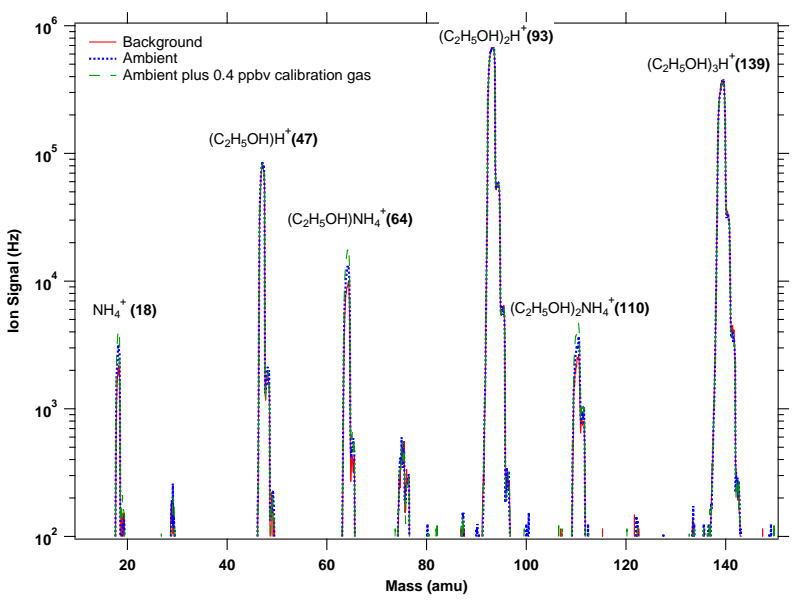

Fig. 2. Typical mass spectra taken for the background (red), ambient (blue dotted), and ambient plus calibration mode (green dashed). The main reagent ion signals were $\left(\mathrm{C}_{2} \mathrm{H}_{5} \mathrm{OH}\right) \mathrm{H}^{+}(47 \mathrm{amu})$, $\left(\mathrm{C}_{2} \mathrm{H}_{5} \mathrm{OH}\right)_{2} \mathrm{H}^{+}(93 \mathrm{amu})$, and $\left(\mathrm{C}_{2} \mathrm{H}_{5} \mathrm{OH}\right)_{3} \mathrm{H}^{+}(139 \mathrm{amu})$, and the main product ion signals were $\mathrm{NH}_{4}^{+}(18 \mathrm{amu}),\left(\mathrm{C}_{2} \mathrm{H}_{5} \mathrm{OH}\right) \mathrm{NH}_{4}^{+}$ $(64 \mathrm{amu})$ and $\left(\mathrm{C}_{2} \mathrm{H}_{5} \mathrm{OH}\right)_{3} \mathrm{NH}_{4}^{+}(110 \mathrm{amu})$. To calculate $\left[\mathrm{NH}_{3}\right]$, we used the main product peak at $64 \mathrm{amu}$ and normalized this with the sum of these three reagent ion signals. Larger clusters as well as weakly bound water clusters $\left[\mathrm{H}_{2} \mathrm{O}\left(\mathrm{C}_{2} \mathrm{H}_{5} \mathrm{OH}\right)_{n} \mathrm{H}^{+}\right]$may also exist, but the use of a collision dissociation chamber (CDC) effectively destroyed these weakly bounded larger ions; ion intensities for peaks at $>150 \mathrm{amu}$ were insignificant.

mixture was then introduced into another PFA tee, with one port connected to the solenoid valve and another port to another PFA tee, located at the downstream of the 3-way valve on the inlet tubing (Fig. 1b). When performing calibration measurements, the solenoid valve was closed and the calibrations gases entered directly into the inlet tubing (green arrow in Fig. 1b). During the ambient/background measurements, the solenoid valve was open and the calibration gases were rapidly removed through the solenoid valve $(50-200 \mathrm{sccm})$ (red arrow in Fig. 1b), to minimize the perturbation of the flow and pressure in the calibration line.

During the fall season, all tubing as well as all tees and valves were also maintained at a constant temperature of $35^{\circ} \mathrm{C}\left( \pm 1.5^{\circ} \mathrm{C}\right)$. This was done by wrapping all the tubing and valves, in aluminum foil which was heated using heating tapes. Keeping the inlet at a constant temperature is important for reducing the uncertainties in the background signals (Sect. 3.2). We have also used only PFA and FEP Teflon materials in the entire inlet system, since stainless steel or other metal materials can easily uptake $\mathrm{NH}_{3}$ on their surfaces (Yokelson et al., 2003b; Nowak et al., 2006, 2007).

\subsection{Ion molecule reaction region}

The ion molecule reaction cell of the CIMS was maintained at a low pressure between 20-25 torr ( 1 torr $=133.3$ Pascal). The total flow into the reactor was between $6.7-7.7 \mathrm{slpm}$, 

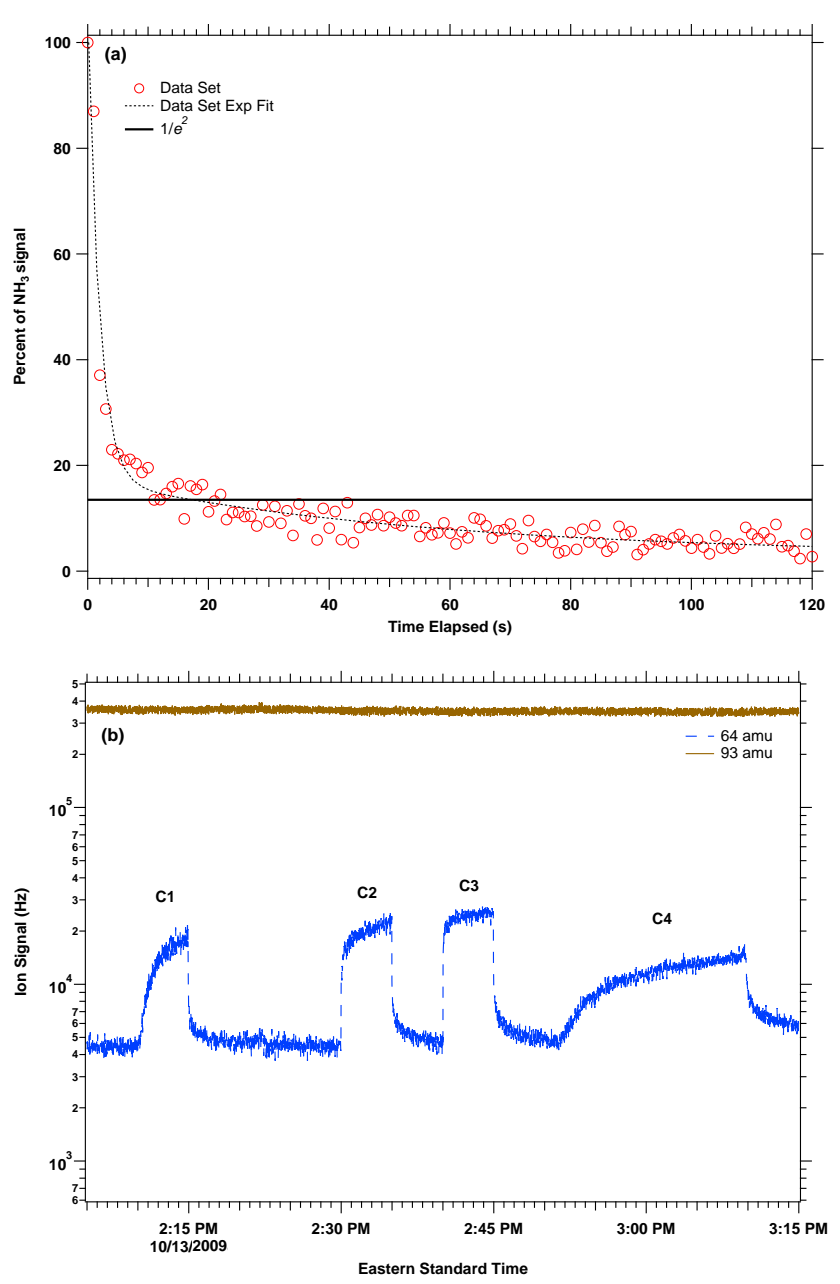

Fig. 3. (a) Signal decay after removal of calibration. One data set was used to calculate the time response of the CIMS instrument. The data set was for a sensitivity of $24.5 \mathrm{~Hz} / \mathrm{pptv}$ (maximum signal was $25000 \mathrm{~Hz}$ ). The black dotted line represents double exponential fits for the data set and the black solid horizontal line $1 / e^{2}$ decay. (b) A measurement sequence, showing four different calibration measurements. Raw ion signals taken with a $1 \mathrm{~s}$ time resolution are shown here. $\left(\mathrm{C}_{2} \mathrm{H}_{5} \mathrm{OH}\right)_{2} \mathrm{H}^{+}, 93 \mathrm{amu}$ (brown); $\left(\mathrm{C}_{2} \mathrm{H}_{5} \mathrm{OH}\right) \mathrm{NH}_{4}^{+}, 64 \mathrm{amu}$ (light blue dashed). $\mathrm{C} 1$ indicates the calibration measurements made using only $1 \mathrm{sccm}$ of $0.8 \mathrm{ppbv} \mathrm{NH}_{3}$ cal-

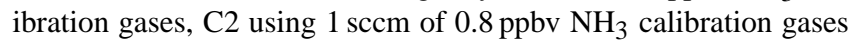
and an additional $50 \mathrm{sccm}$ of $\mathrm{N}_{2}, \mathrm{C} 3 \mathrm{using} 1 \mathrm{sccm}$ of $0.8 \mathrm{ppbv} \mathrm{\textrm {NH } _ { 3 }}$

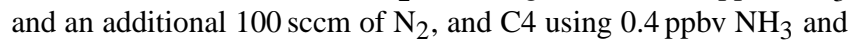
an additional $100 \mathrm{sccm}$ of $\mathrm{N}_{2}$ through the flow tube.

which consisted of the ambient air flow (5.2 slpm) through a $0.8 \mathrm{~mm}$ hole in an $\mathrm{Al}$ sampling cone and the reagent gas flow $(1.5-2.5 \mathrm{slpm})$ perpendicular to the ambient flow. The reagent gas flow consisted of $\mathrm{N}_{2}$ gases and a small percentage $(2-3 \%)$ of ethanol vapor, which was brought by flowing $50 \mathrm{sccm}$ of $\mathrm{N}_{2}$ through a small glass bottle containing $95 \%$ ethanol solution at room temperature. The reaction time in the flow reactor was estimated to be $\sim 40 \mathrm{~ms}$.
The ion source flow was passed over a ${ }^{210}$ Po radioactive source emitting $\alpha$ particles that led to the production of protonated ethanol ions $\left[\left(\mathrm{C}_{2} \mathrm{H}_{5} \mathrm{OH}\right) \mathrm{H}^{+}\right]$and their cluster ions $\left[\left(\mathrm{C}_{2} \mathrm{H}_{5} \mathrm{OH}\right)_{n} \mathrm{H}^{+}\right]$, where $n=1,2,3$, etc. (Nowak et al., 2006). These reagent ions reacted with $\mathrm{NH}_{3}$ under the following pathway (Nowak et al., 2006):

$\left[\left(\mathrm{C}_{2} \mathrm{H}_{5} \mathrm{OH}\right)_{n}\right] \mathrm{H}^{+}+\mathrm{NH}_{3} \rightarrow \mathrm{NH}_{3}\left(\mathrm{C}_{2} \mathrm{H}_{5} \mathrm{OH}\right)_{n-y} \mathrm{H}^{+}+y\left(\mathrm{C}_{2} \mathrm{H}_{5} \mathrm{OH}\right)(\mathrm{R} 1)$

where $y$ is an integer less than $n$. A typical mass spectrum taken from the ambient air is shown in Fig. 2. Primary reagent ions seen in CIMS spectra, in the order of decreasing ion intensity, were protonated ethanol dimer $\left(\mathrm{C}_{2} \mathrm{H}_{5} \mathrm{OH}\right)_{2} \mathrm{H}^{+}(93 \mathrm{amu})$, trimer $\left(\mathrm{C}_{2} \mathrm{H}_{5} \mathrm{OH}\right)_{3} \mathrm{H}^{+},(139 \mathrm{amu})$ and monomer $\left(\mathrm{C}_{2} \mathrm{H}_{5} \mathrm{OH}\right) \mathrm{H}^{+}(47 \mathrm{amu})$. Primary product ions were $\left(\mathrm{C}_{2} \mathrm{H}_{5} \mathrm{OH}\right) \mathrm{NH}_{4}^{+}(64 \mathrm{amu}), \mathrm{NH}_{4}^{+}(18 \mathrm{amu})$ and $\left(\mathrm{C}_{2} \mathrm{H}_{5} \mathrm{OH}\right)_{2} \mathrm{NH}_{4}^{+}(110 \mathrm{amu})$. Only the product ion signal at $64 \mathrm{amu}$ was used for $\left[\mathrm{NH}_{3}\right]$ calculations, since this was the most prominent ion peak (Fig. 2) and gave the best sensitivity. To account for the possible variations in reagent ion signals which were caused by the fluctuation of pressure in the ion-molecule reaction region $(<10 \%)$, we also monitored these primary reagent ions and normalized them when calculating $\left[\mathrm{NH}_{3}\right]$. Reaction rates of these proton transfer ion molecule reactions are very similar to each other, because these are collision limited reactions; this also simplifies normalization of these different reagent ion signals.

The CIMS sensitivity was determined by taking the difference in normalized product ion signals between the calibration and ambient mode, with the amount of the added calibration gases. For the same day, the sensitivity was nearly constant, although there were some day to day variations, likely due to pressure fluctuations in the ionization region. Although the sensitivity varied, this did not affect the accuracy of ambient measurement results (Fig. 5), as will be discussed in Sect. 3.3.

Mass scans (Fig. 2) were performed every several hours to ensure the instrument was running properly. During the normal operation, eight ion peaks including the major reagent and product ions were measured over time. From these measurements, a sequence of the measured data was constructed, including the calibration, background and ambient measurement mode, as shown with ion signals vs. time (Fig. 4a). With the use of the sensitivity and the measured background signals, plots could then be constructed as $\left[\mathrm{NH}_{3}\right]$ vs. time (Figs. 5 and 6). Although the CIMS data were collected at $1 \mathrm{~Hz}$, the median values of $\left[\mathrm{NH}_{3}\right]$ calculated over a minute were used for data analysis.

\section{Evaluation of $\mathrm{NH}_{3}$-CIMS}

\subsection{Time response}

The time response of the instrument was determined in the following manner. By measuring the signal decay from 
removal of a standard addition calibration, the data was fit by an exponential function and the time response was determined from the $1 / \mathrm{e}^{2}$ decay mark (Ryerson et al., 2000). For example, for one of the decays shown in Fig. 3a (sensitivity of $25 \mathrm{~Hz} / \mathrm{pptv}$ ), the fit was:

$\%$ Steady State $\left[\mathrm{NH}_{3}\right]=3+14 e^{-0.018 t}+88 e^{-0.524 t}$

The preexponential terms represent the percentages of the steady state calibration level and $t$ is the time in seconds after removal of the calibration gases. The time required for the signal to reach $1 / \mathrm{e}^{2}(13.5 \%)$ of the initial signal (before calibration termination) was less than $30 \mathrm{~s}$. Another fitting was made for a different sensitivity $(37 \mathrm{~Hz} / \mathrm{pptv})$. The prefactors were within $12 \%$ between the different fittings (the first pre-factor was identical within standard deviation) and the second time constant was within 50\% (the first was identical within standard deviation).

The instrument time response was also tested by using different calibration flow configurations: with only $1 \mathrm{sccm}$ of the calibration gas, a mixture of $1 \mathrm{sccm}$ of the calibration gas and an additional $50 \mathrm{sccm}$ of $\mathrm{N}_{2}$, and a mixture of $1 \mathrm{sccm}$ of the calibration gas and an additional $100 \mathrm{sccm}$ of $\mathrm{N}_{2}$ (Fig. 3b). As shown in Fig. 3b, the signal rise was much faster with the additional $\mathrm{N}_{2}$ flow. Without the additional $\mathrm{N}_{2}$ gases, it took $5 \mathrm{~min}$ to reach the steady state, whereas with the additional flow of $100 \mathrm{sccm}$ of $\mathrm{N}_{2}$, the signal reached the steady state in less than a minute. The net increase in the product ion signal taken with 400 pptv $\mathrm{NH}_{3}$ calibration gases (added via a Pyrex flow tube; $\Delta \mathrm{Hz} \sim 10000 \mathrm{~Hz}$ ) was also approximately half of that with $800 \mathrm{pptv} \mathrm{NH}_{3}$ added directly to the CIMS inlet (Fig. 3b) $(\Delta \mathrm{Hz} \sim 20000 \mathrm{~Hz})$. Calibration gases were added directly to CIMS inlet for calibration measurements (C1-C3 in Fig. 3b) or to our flow tube with the CIMS inlet attached (the flow tube was attached to the very beginning of the inlet) (C4 in Fig. 3b). The response to this addition (C4) shows that there were negligible losses when compared with the other measurements $(\mathrm{C} 1-\mathrm{C} 3)$, indicating the effects of the losses in the inlet before the PFA tee 1 on the derived $\left[\mathrm{NH}_{3}\right]$ were also minimal (Fig. 1b).

\subsection{Background and uncertainty}

Figure $4 \mathrm{a}$ shows a typical measurement sequence including background, calibration and ambient measurements. Background measurements were performed for $5 \mathrm{~min}$ every $30 \mathrm{~min}$ and calibration was performed for $5 \mathrm{~min} \mathrm{ev}$ ery $3 \mathrm{~h}$. For example, for the case shown in this figure, the background mass spectra signals were $\sim 7000 \mathrm{~Hz}$ and the ambient signals are $\sim 9000 \mathrm{~Hz}$. Since the instrument sensitivity was $\sim 15 \mathrm{pptv} / \mathrm{Hz}$ for this specific measurement, we can estimate the background $\left[\mathrm{NH}_{3}\right]$ as $[7000 \mathrm{~Hz} /(15 \mathrm{pptv} / \mathrm{Hz})]=0.46 \mathrm{ppbv}$ and the ambient $\left[\mathrm{NH}_{3}\right]$ as $[(9000 \mathrm{~Hz}-7000 \mathrm{~Hz}) /(15 \mathrm{pptv} / \mathrm{Hz})]=0.13 \mathrm{ppbv}$. This example explains how the background $\mathrm{NH}_{3}$ signals are taken into account for the calculation of ambient $\left[\mathrm{NH}_{3}\right]$.
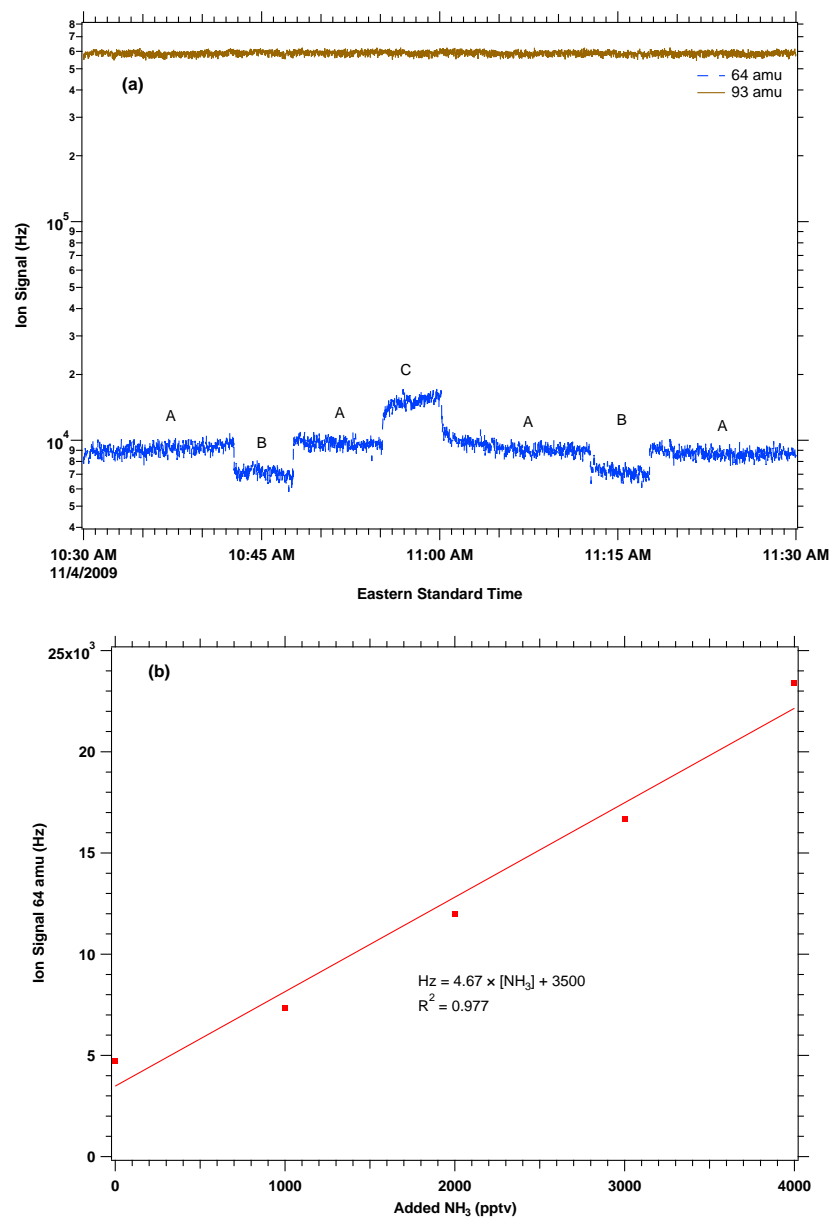

Fig. 4. (a) A typical ambient measurement sequence including the ambient (A), background (B), and calibration mode (C) measurements. Raw ion signals taken with a $1 \mathrm{~s}$ time resolution are shown here. (b) A calibration curve for the CIMS instrument. The air going into the CIMS was from flow tube air (a mixture of nitrogen gas and water vapor with RH 12\%) and entered the CIMS at 5 slpm. The solid line indicates the linear fitting of the measurement data and the slope is the same as the sensitivity.

The background $\left[\mathrm{NH}_{3}\right]$ values were determined with two methods. The first method uses the average $\left[\mathrm{NH}_{3}\right]$ value during a background period (Background 1), and the second method the minimum value (Background 2). The fall and winter data had the best correlation between the two methods, indicating low uncertainties of the signals within the same background period. For the spring data, there was a small difference (13\%) between the two methods and this difference was due to a longer time response for background measurements to reach the steady state. In this study, we used Background 1. The estimated instrument background was usually $<1 \mathrm{ppbv}$ and was $\sim 300 \mathrm{pptv}$ at lowest. The background $\left[\mathrm{NH}_{3}\right]$ varied with the ambient $\left[\mathrm{NH}_{3}\right]$, but there were no clear RH and temperature dependences for the background $\left[\mathrm{NH}_{3}\right]$. 


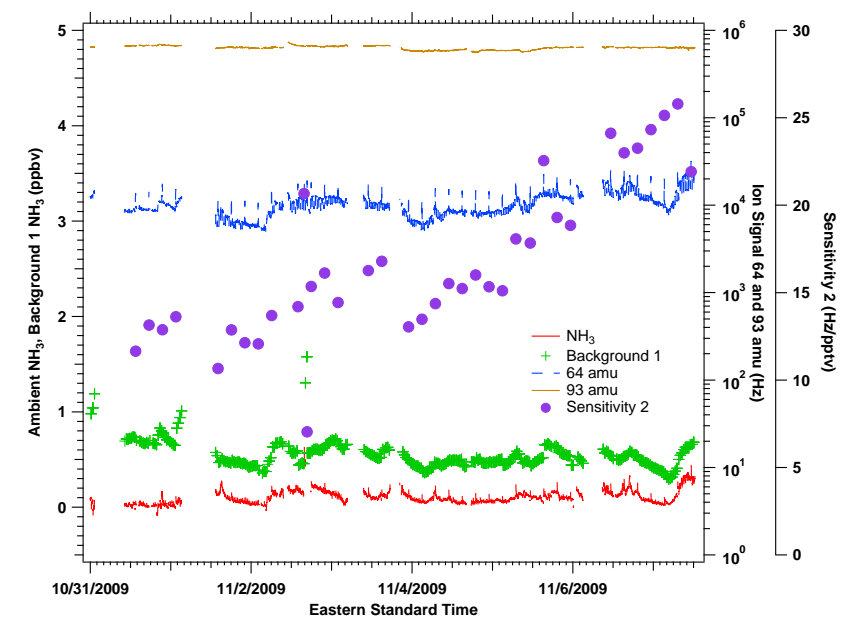

Fig. 5. Ambient measurements taken during the fall of 2009 over an 8 day span. Included are the main product ( $64 \mathrm{amu}$, blue dashed line) and reagent ion mass signals (93 amu, brown solid line), Background 1 (green crosses) and Sensitivity 2 (purple closed circles), and the ambient $\left[\mathrm{NH}_{3}\right]$ (red solid line).

Uncertainties in the background $\left[\mathrm{NH}_{3}\right]$ were estimated by combining one standard deviation $(1 \sigma)$ of $\left[\mathrm{NH}_{3}\right]$ in each background period and the variation in $\left[\mathrm{NH}_{3}\right]$ between two consecutive background measurements (Nowak et al., 2007). For the winter and fall measurements, uncertainties from these two sources together were very low $(30 \mathrm{pptv})$; for the spring, the $1 \sigma$ within the same background period was $\sim 100$ pptv and the average difference between two consecutive backgrounds was $\sim 200 \mathrm{pptv}$. Since the fall measurements were made using a heated inlet system, these results show the importance of heating at a constant temperature.

\subsection{Sensitivity and uncertainty}

Figure $4 \mathrm{~b}$ shows a calibration curve. Flows of $1-4 \mathrm{sccm}$ of the 5 ppmv standard $\mathrm{NH}_{3}$ gases were used to produce calibration concentrations of $1-4 \mathrm{ppbv}$, along with an additional $100 \mathrm{sccm}$ of $\mathrm{N}_{2}$ gases. These calibration gases were introduced into PFA tee 1 right before the CIMS (Fig. 1b). The air entering the CIMS (5.2 slpm) was from flow tube air (a mixture of nitrogen gas and water vapor with RH 12\%). As the curve shows, the CIMS instrument shows a good linear response $\left(R^{2}=0.977\right)$ when different amounts of $\mathrm{NH}_{3}(1-$ 4 ppbv) are added. For this set of calibration measurements, the sensitivity was $4.7 \mathrm{~Hz} / \mathrm{pptv}$.

Calibrations were usually made over 5 min every $3 \mathrm{~h}$. The instrument sensitivity was estimated from calibration measurements with two different methods. For Sensitivity 1, we used the rise between the initial calibration value and the final in a calibration period. Sensitivity 2 was taken by fitting the signal rise during the calibration period and using the maximum value from the fitting. These two methods usually produced similar values (within $<10 \%$ ), signifying that the steady state in the calibration signal was readily achieved within 5 min. In this study, Sensitivity 2 was used. The measured instrument sensitivities varied from $4-25 \mathrm{~Hz} / \mathrm{pptv}$. At present, we don't understand which factors affect the stability of sensitivity; but the accuracy of ambient measurements was unaffected, because changes in sensitivity were measured and accounted for. For example, the calculated $\left[\mathrm{NH}_{3}\right]$ during the fall were always in the sub-ppbv level, regardless of the variation of sensitivity over time (Fig. 5). No clear RH and temperature dependence was observed for the sensitivity.

The uncertainties associated with sensitivity measurements came from several sources, including uncertainties in the mass flow controllers and the $\mathrm{NH}_{3}$ standard gases, as well as the variability in calibration signals. The uncertainty from the mass flow controllers $(<1 \%)$ and the $\mathrm{NH}_{3}$ source cylin$\operatorname{der}(\sim 5 \%)$ were much less than the variability in calibration signals, which varied by season and was found highest for the fall $(\sim 30 \%)$. Thus, the overall uncertainty in the sensitivity was $\sim 30 \%$.

\section{Ambient measurements}

Figure 5 shows the ambient measurements taken during an 8 day period for fall 2009, including the measured raw ion signals (64 amu, the main product ion; $93 \mathrm{amu}$, the main reagent ion), background, sensitivity, and the ambient $\left[\mathrm{NH}_{3}\right]$. The reagent ion signals ranged between $600000-700000 \mathrm{~Hz}$, depending on the pressure in the ion molecule reaction region. The product ion signals varied from $7000-30000 \mathrm{~Hz}$, with the same trend as the reagent ion signals. The background and ambient $\left[\mathrm{NH}_{3}\right]$ during this time period was between 300 $800 \mathrm{pptv}$ and between $60-400 \mathrm{pptv}$, respectively. Again, the background $\left[\mathrm{NH}_{3}\right]$ varied with the same trend as the ambient [ $\left.\mathrm{NH}_{3}\right]$, similarly to (Nowak et al., 2007), but was often higher than the ambient $\left[\mathrm{NH}_{3}\right]$.

The ambient measurements taken for the fall, spring and winter of 2009 are shown in Fig. 6. Overall the median $\left[\mathrm{NH}_{3}\right]( \pm 1 \sigma)$ was $60 \pm 75$ pptv for winter, $200 \pm 120 \mathrm{pptv}$ for spring, and $150 \pm 80 \mathrm{pptv}$ for fall. There was no distinctive diurnal variation for the ambient $\left[\mathrm{NH}_{3}\right]$, although there were some rapid hourly variations. There was also a positive dependence of the ambient $\left[\mathrm{NH}_{3}\right]$ on temperature for all seasons, especially for the winter and spring. The spring had the highest temperatures amongst all seasons studied, which may explain the slightly higher $\left[\mathrm{NH}_{3}\right]$ seen during this season. The $\mathrm{RH}$ dependence for the ambient $\left[\mathrm{NH}_{3}\right]$ was unclear: positive for the winter and negative for the spring and fall.

We have performed backward trajectory calculations using the NOAA HYSPLIT program (Draxler, 2010) and derived the wind direction and speed information from Weather Underground (www.wunderground.com), to see how the air mass history affected the local $\left[\mathrm{NH}_{3}\right]$ level. Trajectories calculations were made for each hour. Our data analysis shows that air masses in Kent often 
originated from northwest in spring and fall and from west/northwest in winter. From the EPA $\mathrm{NH}_{3}$ emission data in this region (http://www.epa.gov/cgibin/broker? _service=airdata\&_program=progs. webprogs.emisdist. scl\&_debug=2\&geotype $=$ st $\&$ geocode $=\mathrm{OH} \&$ geoname $=$ Ohio\&empol=NH3\&emyear=2002_\&emtype $=\&$ emtier $=$ \&emval=a\&mapsize $=z s c \&$ reqtype=viewmap), although the latest data posted are only for 2002, one can expect that air masses traveling from northwest would contain higher $\left[\mathrm{NH}_{3}\right]$. This could also explain why $\left[\mathrm{NH}_{3}\right]$ were higher in spring and fall, but more current emission data are needed to address the transport effects on the local $\left[\mathrm{NH}_{3}\right]$.

\section{Discussion}

There have been four different CIMS instruments used for $\mathrm{NH}_{3}$ detection, reported in the literature (Nowak et al., 2006, 2007; Norman et al., 2007; von Bobrutzki et al., 2010). Table 1 summarizes these $\mathrm{NH}_{3}$-CIMS including the present study, with respect to the sampling inlet and CIMS configuration. While our CIMS was largely based on (Nowak et al., 2006, 2007), in comparison, our CIMS showed lower background signals than the (Nowak et al., 2006)'s low pressure version and higher sensitivities than the (Nowak et al., 2007) version.

When developing a proper inlet for ambient $\mathrm{NH}_{3}$ measurements, there are several key technical issues including the inlet configuration, residence time, and heating. Keeping a straight flow path from the inlet tip to the CIMS can reduce possible $\mathrm{NH}_{3}$ losses on tubing surfaces at the curves. Our inlet configuration was not straight due to the commercial 3 -way valve used in this study (Fig. 1b); we have recently built a custom made 3-way valve from PFA Teflon based on (Neuman et al., 2002; Nowak et al., 2006, 2007) to allow ambient air to flow straight through to the CIMS. It is also important to keep the inlet short and have a high flow, so that the residence time inside the inlet is minimized. Heating the entire inlet system at a constant temperature is also important for the inlet, since this prevents temperature fluctuations, which may lead to adsorption/desorption of $\mathrm{NH}_{3}$ on the inlet walls and affect the instrument background and stability (Nowak et al., 2007). As long as the inlet temperature is above ambient temperature, adsorption of $\mathrm{NH}_{3}$ (due to being close to the dew point) should not occur. Higher temperatures may be used, but temperatures that are too high could result in volatilization of $\mathrm{NH}_{4} \mathrm{NO}_{3}$. Inlet configurations can also affect signals, as condensation in the tubing can lead to $\mathrm{NH}_{3}$ losses (Norman et al., 2009). The sampling line effects, such as $\mathrm{RH}$ and $\mathrm{NH}_{3}$ concentrations, can also play a role in background measurements (Ellis et al., 2010), although in our case the background signals did not have a clear dependence on $\mathrm{RH}$, but varied with the sampled $\mathrm{NH}_{3}$ level.

The reagent ions used in these CIMS were protonated ethanol $\left(\mathrm{CH}_{3} \mathrm{CH}_{2} \mathrm{OH} \cdot \mathrm{H}^{+}\right)$, protonated acetone (both
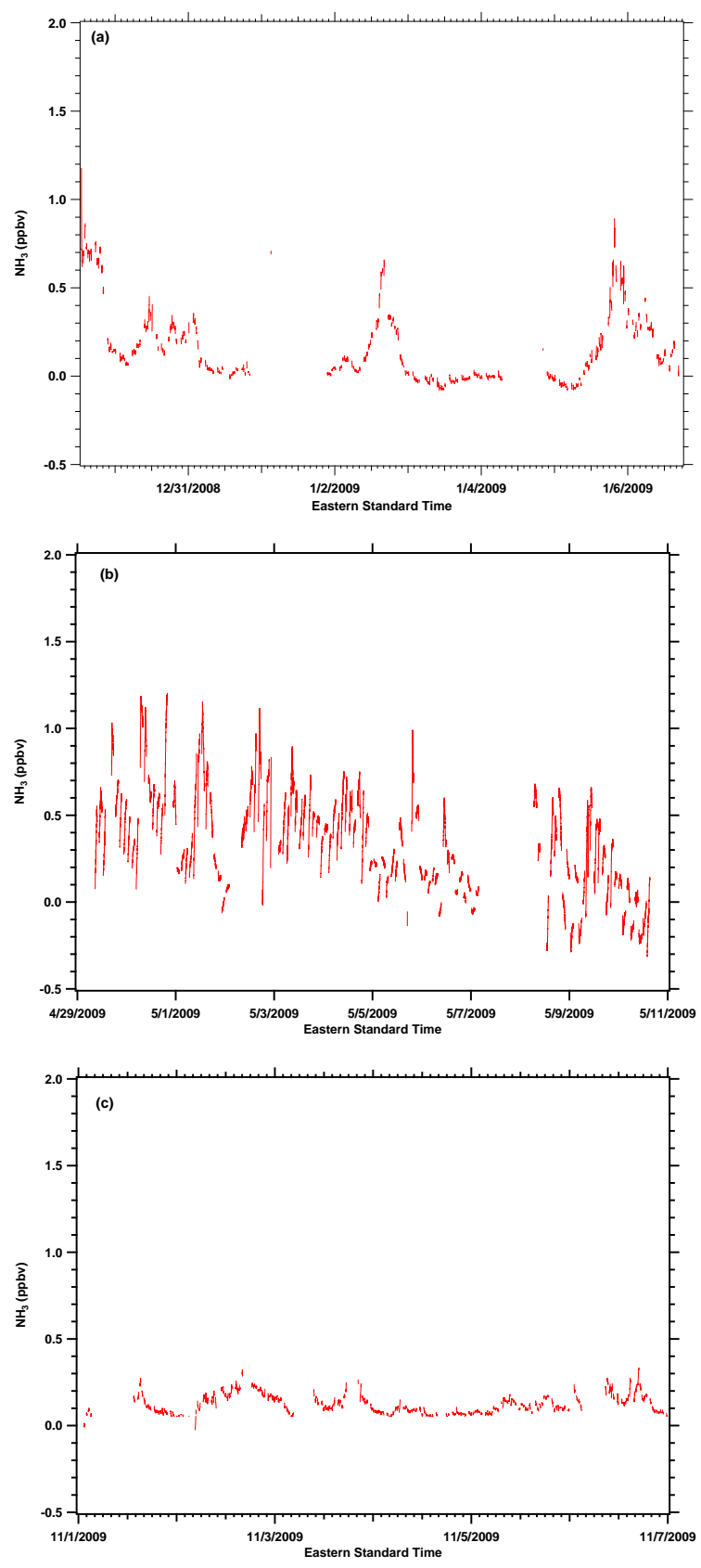

Fig. 6. The ambient $\left[\mathrm{NH}_{3}\right]$ measured in Kent, Ohio, during the winter over an 8 day span (a), during the spring for 12 days (b), and during the fall for 6 days (c) .

$\mathrm{CH}_{3} \mathrm{COCH}_{3} \cdot \mathrm{H}^{+}$and $\left.\mathrm{H}^{+}\left(\mathrm{C}_{3} \mathrm{H}_{6} \mathrm{O}\right)_{2}\right)$, and positive oxygen $\left(\mathrm{O}_{2}^{+}\right)$(Table 1). The main difference amongst them was that in the first two cases, the product ions consisted of $\mathrm{NH}_{4}^{+}$and its protonated cluster ions $\left(\mathrm{NH}_{3}\left(\mathrm{C}_{2} \mathrm{H}_{5} \mathrm{OH}\right)_{n} \mathrm{H}^{+}\right.$, for example), whereas the third method employed electron transfer to produce $\mathrm{NH}_{3}^{+}$. One reason for choosing the $\mathrm{O}_{2}^{+}$method was that the use of $\mathrm{O}_{2}^{+}$can possibly limit the amount of background signals produced in the ion source 
region .(Norman et al., 2007). For the $\mathrm{NH}_{4}^{+}$/proton cluster methods, the residence time was in the $20-160 \mathrm{~ms}$ range, whereas for the $\mathrm{O}_{2}^{+}$method, a much shorter residence time $(0.1-0.15 \mathrm{~ms})$ was used to minimize the secondary reactions involving $\mathrm{NH}_{3}^{+}$(Norman et al., 2007). The sensitivity and background were also different between these two techniques. For the $\mathrm{NH}_{4}^{+}$/proton cluster method, the instrument sensitivity $(1-40 \mathrm{~Hz} / \mathrm{pptv})$ and the background [NH 3 (up to 2 ppbv) both were higher than those in the electron transfer scheme $(0.04 \mathrm{~Hz} / \mathrm{pptv}$ sensitivity and up to $0.47 \mathrm{ppbv}$ background). While the protonated ethanol ions $\left(\mathrm{CH}_{3} \mathrm{CH}_{2} \mathrm{OH} \cdot \mathrm{H}^{+}\right)$can give higher sensitivity, the protonated acetone ions $\left(\mathrm{CH}_{3} \mathrm{COCH}_{3} \cdot \mathrm{H}^{+}\right)$can be less prone to $\mathrm{NH}_{3}$ contamination (Huey, 2007; Nowak et al., 2007). In the present study, we have used the protonated ethanol and obtained moderate sensitivities as well as relatively low background signals. Most of these CIMS instruments utilized a low pressure ( $<25$ torr) in the reaction region (Table 1$)$, although there are also advantages with atmospheric pressure chemical ionization which provides an enhanced sensitivity (Huey, 2007).

There were certain degrees of variations both in background signals and sensitivity in our CIMS. Background signals usually had the same trends as ambient $\mathrm{NH}_{3}$ levels, indicating that there were some effects of adsorption and desorption of $\mathrm{NH}_{3}$ on surfaces inside the inlet, but such effects were taken into account by using background measurements to effectively minimize the artifact effects. Sensitivity also varied day to day, but the measured $\left[\mathrm{NH}_{3}\right]$ levels did not vary over time as sensitivity did, indicating that the varying sensitivity indeed did not affect the accuracy of the ambient $\left[\mathrm{NH}_{3}\right]$ values. In the present study, we did not make intercomparison tests with other $\mathrm{NH}_{3}$ instruments. However, the intercomparison made during the Summer of 2009 in the Michigan forest using our CIMS technique and a wet scrubbing method coupled with long-path absorbance photometry (employed by Xianliang Zhou from State University of New York - Albany) showed that this CIMS technique provides reliable $\mathrm{NH}_{3}$ measurements. For example, the $\left[\mathrm{NH}_{3}\right]$ measured over an 8 day period showed similar results with these two independent methods within experimental uncertainties. A detailed description of these intercomparison results is discussed in (Kanawade et al., 2010).

The $\left[\mathrm{NH}_{3}\right]$ measured in Kent was usually below $1 \mathrm{ppbv}$ for all seasons (Fig. 6). By comparing with other studies cited here, Kent seems to fall into the range of a typical rural region, with regard to the ambient $\left[\mathrm{NH}_{3}\right]$ level. For example, $\left[\mathrm{NH}_{3}\right]$ in the remote marine atmosphere were $86 \mathrm{pptv}$ on average (Schlesinger and Hartley, 1992) and as low as $20 \mathrm{pptv}$ in some remote areas (Dentener and Crutzen, 1994). Rural regions in the eastern United States have shown $\left[\mathrm{NH}_{3}\right]$ of 100-500 pptv (Dentener and Crutzen, 1994) with a mean $\left[\mathrm{NH}_{3}\right]$ of 300 pptv (Langford et al., 1992). Global $\mathrm{NH}_{3}$ emission data taken with infrared satellite observations show that concentrations in the eastern United States are low and no significant hotspots exist in this region (Clarisse et al., 2009). On the other hand, polluted areas have shown $\left[\mathrm{NH}_{3}\right]$ as high as $30 \mathrm{ppbv}$ (Dentener and Crutzen, 1994) and $\left[\mathrm{NH}_{3}\right]$ up to $430 \mathrm{ppbv}$ have been seen in strong point source locations (Schlesinger and Hartley, 1992). Emission measurements made in different automobile tunnels have shown $\left[\mathrm{NH}_{3}\right]$ of 50-400 ppbv (Fraser and Cass, 1998; Kean et al., 2000; Moeckli et al., 2004) $\left[\mathrm{NH}_{3}\right]$ of $20-70$ ppbv have also been reported from smoke (Yokelson et al., 1999, 2003; Goode et al., 2000), as well as 100-200 ppbv in biomass burning plumes (Hurst et al., 1994; Li et al., 2006).

A possible reason for the low levels of $\mathrm{NH}_{3}$ is uptake by sulfuric acid aerosols. If high acidity of aerosols was present, this would uptake and neutralize $\mathrm{NH}_{3}$. A precursor for sulfuric acid is $\mathrm{SO}_{2}$. One study (Sorooshian et al., 2006) made during the ICARTT experiments, showed that when flying over the Cleveland area $\mathrm{SO}_{2}$ emitted from power plant plumes was as high as $70 \mathrm{ppbv}$ and that the ammonium-to-sulfate ratio indicated insufficient amounts of $\mathrm{NH}_{3}$ present so the high levels of sulfuric acid present would not be neutralized. $\mathrm{SO}_{2}$ emissions in Ohio generally ranks amongst the top in the nation (http://www.epa.gov/air/sulfurdioxide/) because of the strong $\mathrm{SO}_{2}$ emission from large size coal-burning power plants in this region (http://www.epa.gov/cgi-bin/broker? _service=airdata_\&_program=progs.webprogs.emisumry. scl\&_debug=2\&geotype $=$ st $\&$ geocode $=\mathrm{OH} \&$ geoname $=$ Ohio\&epolmin $=. \&$ epolmax $=. \&$ epol $=\mathrm{SO} 2 \backslash \& \mathrm{sic}=\&$ netyr $=$ 2002\&geofeat=\&mapsize=zsc\&reqtype=getmap); typically, the reported $\mathrm{SO}_{2}$ concentrations were nearly at the ppbv or tens of ppbv range all year around in Akron and Cleveland in recent years. Data taken from the Ozone Monitoring Instrument on the NASA EOS Aura platform (Krotkov et al., 2006) showed the average $\mathrm{SO}_{2}$ concentration $( \pm 1 \sigma)$ as $0.7 \pm 1.3$ Dobson units (DU; $1 \mathrm{DU} \approx 1 \mathrm{ppbv}$ ) for the winter, $0.3 \pm 0.13 \mathrm{DU}$ for the spring, and $0.5 \pm 0.52 \mathrm{DU}$ for the fall in the planetary boundary layer in Kent, Ohio. These values were anticorrelated with the median $\left[\mathrm{NH}_{3}\right]( \pm 1 \sigma)$ values $(60 \pm 75 \mathrm{pptv}$ for winter, $200 \pm 120 \mathrm{pptv}$ for spring, and $150 \pm 80$ pptv for fall), showing that when $\left[\mathrm{SO}_{2}\right]$ is higher, $\left[\mathrm{NH}_{3}\right]$ is lower. This could be explained by removal of $\mathrm{NH}_{3}$ through uptake by acidic aerosols (typically sulfuric acid in this region) via neutralization.

$\mathrm{NH}_{3}$ has been used to theoretically explain new particle formation in the eastern US (Stanier et al., 2004; Gaydos et al., 2005; Lucas and Akimoto, 2006; Jung et al., 2008). As discussed in (Erupe et al., 2010), we also have made ternary homogeneous nucleation simulations using (Merikanto et al., 2007)' $\mathrm{H}_{2} \mathrm{SO}_{4}-\mathrm{NH}_{3}-\mathrm{H}_{2} \mathrm{O}$ ternary homogeneous nucleation parameterizations and using the measured $\mathrm{H}_{2} \mathrm{SO}_{4}$ and $\mathrm{NH}_{3}$ concentrations taken in Kent, but the model could not reproduce the atmospherically measured nucleation rates. These results suggest that these nucleation parameterizations need to be constrained by observations. 


\section{Conclusions}

We have characterized the instrumental performance of our new $\mathrm{NH}_{3}$-CIMS. The CIMS sensitivity ranged from 4$25 \mathrm{~Hz} /$ pptv with an uncertainty of $30 \%$ for $>1 \mathrm{MHz}$ reagent ion signals. The background $\left[\mathrm{NH}_{3}\right]$ was in the range from $0.3-1 \mathrm{ppbv}$ with an uncertainty of $30 \mathrm{pptv}$ under optimized measurement conditions. The detection limit of the instrument was estimated to be about 60 pptv ( 1 min integration time and 3 sigma deviation) and the instrument time response was $<30 \mathrm{~s}$. This new $\mathrm{NH}_{3}$-CIMS has been used for ambient observations in Kent, Ohio during several weeks crossing three seasons. $\left[\mathrm{NH}_{3}\right]$ was higher during the spring $(200 \pm 120$ pptv) than in winter $(60 \pm 75$ pptv) and fall (150 \pm $80 \mathrm{pptv}$ ). It should be noted that some degree of bias may also exist due to variations of the inlet setup from season to season so cautions should be taken when looking at seasonal variations. While our CIMS demonstrated sensitivity sufficient for ambient measurements, there is large room for improvement. For example, the inlet residence time can be further reduced by shortening the tubing length. We are also improving our heating system to minimize temperature fluctuations in the inlet.

Acknowledgements. We gratefully acknowledge funding support from NOAA (NA08OAR4310537), NSF (CAREER ATM0645567; ATM-0904144) and Ohio Board Regents. We also thank Greg Huey and David Tanner for technical support on CIMS and thank John Nowak, Bob Yokelson, Mark Erupe and Vijay Kanawade for useful discussions. The Dutch-Finnish built OMI instrument is part of the NASA EOS Aura satellite payload. The OMI instrument is managed by Royal Dutch Meteorological Institute (KNMI) and the Netherlands Agency for Aerospace Programs (NIVR). We acknowledge NASA Goddard Earth Sciences Data and Information Services Center (GES DISC) for providing OMI L2G $\mathrm{SO}_{2}$ data for this study. We also acknowledge the NOAA Air Resources Laboratory (ARL) for the provision of the HYSPLIT transport and dispersion model and READY website (http://www.arl.noaa.gov/ready.php) used in this publication.

Edited by: R. Cohen

\section{References}

Ball, S. M., Hanson, D. R., Eisele, F. L., and McMurry, P. H.: Laboratory studies of particle nucleation: Initial results for $\mathrm{H}_{2} \mathrm{SO}_{4}$, $\mathrm{H}_{2} \mathrm{O}$, and $\mathrm{NH}_{3}$ vapors, J. Geophys. Res., 104, 23709-23718, 1999.

Benson, D. R., Erupe, M. E., and Lee, S.-H.: Laboratorymeasured $\mathrm{H}_{2} \mathrm{SO}_{4}-\mathrm{H}_{2} \mathrm{O}-\mathrm{NH}_{3}$ ternary homogenous nucleation rates: Initial observations, Geophys. Res. Lett., 36, L15818, doi:10.1029/2009GL038728, 2009.

Benson, D. R., Young, L. H., Kameel, R., and Lee, S.-H.: Laboratory-Measured Sulfuric Acid and Water Homogeneous Nucleation Rates from the $\mathrm{SO}_{2}+\mathrm{OH}$ Reaction, Geophys. Res. Lett., 35, L11801, doi:11810.11029/12008GL033387, 2008.
Clarisse, L., Clerbaux, C., Dentener, F., Hurtmans, D., and Coheur, P.-F.: Global ammonia distribution derived from infrared satellite observations, Nature Geosci., 2, 479-483, 2009.

Dentener, F. J., and Crutzen, F.: A three-dimensional model of the global ammonia cycle J. Atmos. Chem., 19, 331-369, 1994.

Draxler, R. R. and Rolph, G. D.: HYSPLIT (HYbrid Single-Particle Lagrangian Integrated Trajectory) Model access via NOAA ARL READY Website (http://ready.arl.noaa.gov/HYSPLIT.php), Silver Spring, MD, NOAA Air Resources Laboratory, 2010.

Eisele, F. L. and Tanner, D. J.: Measurements of gas phase concentrations of $\mathrm{H}_{2} \mathrm{SO}_{4}$ and methane sulfonic acid and estimates of $\mathrm{H}_{2} \mathrm{SO}_{4}$ production and loss in the atmosphere, J. Geophys. Res., 98, 9001-9010, 1993.

Ellis, R. A., Murphy, J. G., Pattey, E., van Haarlem, R., O’Brien, J. M., and Herndon, S. C.: Characterizing a Quantum Cascade Tunable Infrared Laser Differential Absorption Spectrometer (QCTILDAS) for measurements of atmospheric ammonia, Atmos. Meas. Tech., 3, 397-406, doi:10.5194/amt-3-397-2010, 2010.

Erupe, M. E., Benson, D. R., Li, J., Young, L.-H., Verheggen, B., Al-Refai, M., Tahboub, O., Cunningham, V., Frimpong, F., Viggiano, A. A., and Lee, S.-H.: Correlation of Aerosol Nucleation Rate with Sulfuric Acid and Ammonia in: Kent Ohio: An Atmospheric Observation, doi:10.1029/2010JD013942, 2010.

Fehsenfeld, F. C., Huey, L. G., Leibrock, E., Dissley, R., Williams, E., Ryerson, T. B., Norton, R., Sueper, D. T., and Hartsell, B.: Results from an informal intercomparison of ammonia measurement techniques J. Geophys. Res., 107, 4812-4819, doi:4810.1029/2001JD001327, 2002.

Ferm, M., Areskoug, H., Hanssen, J.-E., Hilbert, G., and Lattila, H.: Field Intercomparison of Measurement Techniques for Total $\mathrm{NH}_{4}^{+}$and Total $\mathrm{NO}_{3}^{-}$in Ambient Air, Atmos. Environ., 22(10), 2275-2281, 1988.

Fraser, M. P. and Cass, G. R.: Detection of excess ammonia emissions from in-use vehicles and the implications for fine particle control, Environ. Sci. Technol., 32, 1053-1057, 1998.

Gaydos, T. M., Stainer, C. O., and Pandis, S. N.: Modeling of in situ ultrafine atmospheric particle formation in the eastern United States, J. Geophys. Res., 110, D07S12, doi:10.1029/2004JD004683, 2005.

Gilliland, A. B., Dennis, R. L., Roselle, S. J., and Pierce, T. E.: Seasonal $\mathrm{NH}_{3}$ emission estimates for the eastern United States based on ammonium wet concentrations and an inverse modeling method, J. Geophys. Res., 108, 4477, doi:4410.1029/2002JD003063, 2003.

Goode, J. G., Yokelson, R. J., Ward, D. E., Susott, R. A., Babbit, R. E., Davies, M. A., and Hao, W. M.: Measurements of excess $\mathrm{O}_{3}, \mathrm{CO}_{2}, \mathrm{CH}_{4}, \mathrm{C}_{2} \mathrm{H}_{4}, \mathrm{HCN}, \mathrm{NO}, \mathrm{NH}_{3}, \mathrm{HCOOH}, \mathrm{CH}_{3} \mathrm{COOH}$, $\mathrm{HCHO}$, and $\mathrm{CH}_{3} \mathrm{H}$ in 1997 Alaskan biomass burning plumes by airborne Fourier transform infrared spectroscopy, J. Geophys. Res., 105, 22417-22166, 2000.

Herndon, S. C., Jayne, J. T., Zahniser, M. S., Worsnop, D. R., Knighton, B., Alwine, E., Lamb, B. K., Zavala, M., Nelson, D. D., McManus, J. B., Shorter, J. H., Canagaratna, M. R., Onasch, T. B., and Kolb, C. E.: Characterization of urban pollutant emission fluxes and ambient concentration distributions using a mobile laboratory with rapid response instrumentation, Faraday Discuss., 130, 327-339, 2005.

Huai, T., Durbin, T. D., Miller, J. W., Pisano, J. T., Saucer, C. G., Rhee, S. H., and Norbeck, J. M.: Investigation of $\mathrm{NH}_{3}$ emissions 
from new technology vehicles as a function of vehicles as a function of vehicle operating conditions, Environ. Sci. Technol., 37, 4841-4847, 2003.

Huey, L. G.: Measurement of trace atmospheric species by chemical ionization mass spectrometry: Speciation of reactive nitrogen and recent developments, Mass Spectrom. Rev., 26, 166-184, 2007.

Hurst, D. F., Griffith, D. W. T., Carras, J. N., Williams, D. J., and Freser, P. J.: Measurements of trace gases emitted by Australian savanna fires during the 1990 dry season, J. Atmos. Chem., 18, 33-56, 1994.

Jung, J. G., Pandis, S. N., and Adams, P. J.: Evaluation of Nucleation Theories in a Sulfur-Rich Environment, Aerosol Sci. Technol., 42, 495-504, 2008.

Kean, A. J., Harley, R. A., Littlejohn, D., and Kendall, G. R.: Onroad measurement of ammonia and other motor vehicle exhaust emissions Environ. Sci. Technol., 34, 3535-3539, 2000.

Krotkov, N. A., Carn, S. A., Krueger, A. J., Bhartia, P. K., and Yang, K.: Band Residual Difference Algorithm for Retrieval of $\mathrm{SO}_{2}$ From the Aura Ozone Monitoring Instrument (OMI), IEEE Transactions on Geoscience and Remote Sensing, 44(5), 12591266, 2006.

Langford, A. O., Golden, P. D., and Fehsenfeld, F. C.: A molybdenum oxide annular denuder system for gas-phase ambient ammonia measurement J. Atmos. Chem., 8, 359-376, 1989.

Lebel, P. J., Hoell, J. M., Levine, J. S., and Vay, S. S.: Aircraft measurements of ammonia and nitric acid in the lower troposphere, Geophys. Res. Lett., 12, 401-404, 1985.

Li, Y., Schwab, J. J., and Demerijian, K. L.: Measurements of ambient ammonia using a tunable diode laser absorption spectrometer: Characteristics of ambient ammonia emissions in an urban area of New York City, J. Geophys. Res., 111, D10S02, doi:10.1029/2005JD006275, 2006.

Lucas, D. D. and Akimoto, H.: Evaluating aerosol nucleation parameterization in a global atmospheric model, Geophys. Res. Lett., 33, L10808, doi:10810.11029/12006GL025672, 2006.

McMurry, P. H., Fink, M., Sakuri, H., Stolzenburg, M., Mauldin III, R. L., Smith, J., Eisele, F. L., Moore, K., Sjostedt, S., Tanner, D., Huey, L. G., Nowak, J. B., Edgerton, E., and Voisin, D.: A criterion for new partricle formation in the sulfur-rich Atlanta atmosphere, J. Geophys. Res., 110, D22S02, doi:10.1029/2005JD005901, 2005.

Merikanto, J., Napari, I., Vehkamäki, H., Anttila, T., and Kulmala, M.: New parameterization of sulfuric acid-ammonia-water ternary nucleation rates at tropospheric conditions, J. Geophys. Res., 112, D15207, doi:15210.11029/12006JD007977, 2007.

Moeckli, M., Fierz, M., and Sigritism, M. W.: Emissions factors for ethane and ammonia from a tunnel study with a photoacoustic trace gas detection system, Environ. Sci. Technol., 30, 2864 2867, 2004.

Neuman, J. A., Huey, L. G., Dissly, R. W., Fehsenfeld, F. C., Flocke, F., Holecek, J. C., Holloway, J. S., Hubler, G., Jakoubek, R., Nicks Jr., D. K., Parrish, D. D., Ryerson, T. B., Sueper, D. T., and Weinheimer, A. J.: Fast-response airborne in situ measurements $\mathrm{HNO}_{3}$ during the Texas 2000 Air Quality Study, J. Geophys. Res., 107(D20), doi:10.1029/2001JD001437, 2002.

Norman, M., Hansel, A., and Wisthaler, A.: $\mathrm{O}_{2}^{+}$as reagent ion in the PTR-MS instrument: Detection of gas-phase ammonia, Int. J. Mass Spectrom., 265, 382-387, 2007.
Norman, M., Spirig, C., Wolff, V., Trebs, I., Flechard, C., Wisthaler, A., Schnitzhofer, R., Hansel, A., and Neftel, A.: Intercomparison of ammonia measurement techniques at an intensively managed grassland site (Oensingen, Switzerland), Atmos. Chem. Phys., 9, 2635-2645, doi:10.5194/acp-9-2635-2009, 2009.

Nowak, J. B., Huey, L. G., Russell, A. G., Tian, D., Neuman, J. A., Orsini, D., Sjostedt, S. J., Sullivan, A. P., Tanner, D. J., Weber, R. J., Nenes, A., Edgerton, E., and Fehsenfeld, F. C.: Analysis of urban gas phase ammonia measurements from the 2002 Atlanta Aerosol Nucleation and Real-Time Characterization Experiment (ANARChE), J. Geophys. Res., 111, D17308, doi:17310.11029/12006JD007113, 2006.

Nowak, J. B., Newman, J. A., Kozai, K., Huey, L. G., Tanner, D., Holloway, J. S., Ryerson, T. B., Frost, G. L., McKeen, S. A., and Fehsenfeld, F. C.: A chemical ionization mass spectrometry technique for airborne measurements of ammonia J. Geophys. Res., 112, D10S02, doi:10.1029/2006JD007589, 2007.

Quinn, P. K. and Bates, T. S.: Collection efficiences of a tandem sampling system for atmospheric aerosol particles and gaseous ammonia and sulfur dioxide, Environ. Sci. Technol., 23, 736739, 1989.

Ryerson, T. B., Williams, E. J., and Fehsenfeld, F. C.: An efficient photolysis system for fast response $\mathrm{NO}_{2}$ measurements, J. Geophys. Res., 105(D21), 26447-26461, 2000.

Schlesinger, W. H. and Hartley, A. E.: A global budget for atmospheric $\mathrm{NH}_{3}$, Biogeochemistry, 15, 191-211, 1992.

Schwab, J. J., Li, Y., Bae, M.-S., Demerjian, K. L., Hou, J., Zhou, X., Jensen, B., and Pryor, S. C.: A Laboratory Intercomparison of Real-Time Gaseous Ammoni Measurement Methods, Environ. Sci. Technol., 41(24), 8412-8419, 2007.

Slusher, D. 1., Huey, L. G., Tanner, D. J., Flocke, F. M., and Roberts, J. M.: A thermal dissociation-chemical ionization mass spectrometry (TD-CIMS) technique for the simultaneous measurement of peroxyacyl nitrates and dinitrogen pentoxide, J. Geophys. Res., 109, doi:10.1029/2004JD004670, 2004.

Smith, J. N., Moore, K., Eisele, F. L., Voisin, D., Ghimire, A. K., Sakuri, H., and McMurry, P. H.: Chemical composition of atmospheric nanoparticles during nucleation in Atlanta, J. Geophys. Res., 110, D22S03, doi:10.1029/2005JD005912, 2005.

Sorooshian, A., Varutbangkul, V., Brechtel, F. J., Ervens, B., Feingold, G., Bahreini, R., Murphy, S. M., Holloway, J. S., Atlas, E. L., Buzorius, G., Jonsson, H., Flagan, R. C., and Seinfeld, J. H.: Oxalic acid in clear and cloudy atmospheres: Analysis of data from International Consortium for Atmospheric Research on Transport and Transformation 2004, J. Geophys. Res., 111, D23S45, 2006.

Stanier, C. O., Kylstov, A. Y., and Pandis, S. N.: Nucleation events during the Pittsburgh air quality study: Description and relation to key meteorological, gas phase, and aerosol parameters, Aerosol Sci. Tech, 38, 253-264, 2004.

Thomas, R. M., Trebs, I., Otjes, R., Jongejan, P. A. C., Brink, H. T., Phillips, G., Kortner, M., Meixner, F. X., and Nemitz, E.: An Automated Analyzer to Measure Surface-Atmosphere Exchange Fluxes of Water Soluble Inorganic Aerosol Compounds and Reactive Trace Gases, Environ. Sci. Technol., 43, 1412-1418, 2009. van Dijk, C. A., Sandholm, S. T., Davis, D. D., and Bradshaw, J. D.: $\mathrm{NH}\left(\mathrm{b}^{1} \Sigma^{+}\right)$deactivation/reaction rate constants for the collisional gases $\mathrm{H}_{2}, \mathrm{CH}_{4}, \mathrm{C}_{2} \mathrm{H}_{6}, \mathrm{Ar}, \mathrm{N}_{2}, \mathrm{O}_{2}, \mathrm{H}_{2} \mathrm{O}$ and $\mathrm{CO}_{2}$, J. Phys. Chem., 93, 6363-6767, 1989. 
von Bobrutzki, K., Braban, C. F., Famulari, D., Jones, S. K., Blackall, T., Smith, T. E. L., Blom, M., Coe, H., Gallagher, M., Ghalaieny, M., McGillen, M. R., Percival, C. J., Whitehead, J. D., Ellis, R., Murphy, J., Mohacsi, A., Pogany, A., Junninen, H., Rantanen, S., Sutton, M. A., and Nemitz, E.: Field inter-comparison of eleven atmospheric ammonia measurement techniques, Atmos. Meas. Tech., 3, 91-112, doi:10.5194/amt-3-91-2010, 2010.

Weber, R. J., Marti, J. J., McMurry, P. H., Mauldin III, R. L., Tanner, D., Eisele, F. L., Brechtel, F., Kreidenweis, S. M., Kok, G., Schillawski, R. D., and Baumgardner, D.: A study of new particle formation and growth involving biogenic and trace gas species measured during ACE 1, J. Geophys. Res., 103, 1638516396, 1998.

Yokelson, R. J., Bertschi, I. T., Christian, T. J., Hobbs, P. V., Ward, D. E., and Hao, W. M.: Trace gas measurements in nascent, aged, and cloud processed smoke from African savanna fires by airborne Fourier transform infrared spectroscopy (AFTIR), J. Geophys. Res., 108(D13), 8478, doi:8410.1029/2002JD002322, 2003.
Yokelson, R. J., Christian, T. J., Bertschi, I. T., and Hao, W. M.: Evaluation of adsorption effects on measurements of ammonia, acetic acid, and methanol, J. Geophys. Res., 108(D20), doi:10.1029/2003JD003549, 2003b.

Yokelson, R. J., Goode, J. G., Ward, D. E., Susott, R. A., Babbitt, R. E., Wade, D. D., Bertschi, I., Griffith, D. W. T., and Hao, W. M.: Emissions of formaldehyde, acetic acid, methanol, and other trace gases from biomass fires in North Carolina measured by airborne Fourier transform infrared spectroscopy, J. Geophys. Res., 104, 30109-30126, 1999.

Young, L. H., Benson, D. R., Kameel, F. R., Pierce, J. R., Junninen, H., Kulmala, M., and Lee, S.-H.: Laboratory studies of $\mathrm{H}_{2} \mathrm{SO}_{4} / \mathrm{H}_{2} \mathrm{O}$ binary homogeneous nucleation from the $\mathrm{SO}_{2}+\mathrm{OH}$ reaction: evaluation of the experimental setup and preliminary results, Atmos. Chem. Phys., 8, 4997-5016, doi:10.5194/acp-84997-2008, 2008. 